\title{
Characterization of Apricot pseudo-chlorotic leaf spot virus, A Novel Trichovirus Isolated from Stone Fruit Trees
}

\author{
D. Liberti, A. Marais, L. Svanella-Dumas, M. J. Dulucq, D. Alioto, A. Ragozzino, B. Rodoni, and T. Candresse
}

First, fifth, and sixth authors: Dipartimento di Arboricoltura, Botanica e Patologia Vegetale, Università degli Studi di Napoli Federico II, 80055 Portici, Napoli, Italy; second, third, fourth, and eighth authors: Equipe de Virologie, UMR GD2P, INRA et Université Bordeaux 2, IBVM, Campus INRA, BP81, 33883 Villenave d'Ornon Cedex, France; and seventh author: Department of Primary Industries, 621 Burwood Highway, Knoxfield, Victoria, 3156 Australia.

Accepted for publication 17 December 2004.

\begin{abstract}
Liberti, D., Marais, A., Svanella-Dumas, L., Dulucq, M. J., Alioto, D., Ragozzino, A., Rodoni, B., and Candresse, T. 2005. Characterization of Apricot pseudo-chlorotic leaf spot virus, a novel trichovirus isolated from stone fruit trees. Phytopathology 95:420-426.

A trichovirus closely related to Apple chlorotic leaf spot virus (ACLSV) was detected in symptomatic apricot and Japanese plum from Italy. The Sus 2 isolate of this agent cross-reacted with anti-ACLSV polyclonal reagents but was not detected by broad-specificity antiACLSV monoclonal antibodies. It had particles with typical trichovirus morphology but, contrary to ACLSV, was unable to infect Chenopodium quinoa and C. amaranticolor. The sequence of its genome (7,494 nucleo-

partial sequence of another isolate were determined. The new virus has a genomic organization similar to that of ACLSV, with three open reading frames coding for a replication-associated protein (RNA-dependent RNA polymerase), a movement protein, and a capsid protein, respectively. However, it had only $\approx 65$ to $67 \%$ nucleotide identity with sequenced isolates of ACLSV. The differences in serology, host range, genome sequence, and phylogenetic reconstructions for all viral proteins support the idea that this agent should be considered a new virus, for which the name Apricot pseudo-chlorotic leaf spot virus (APCLSV) is proposed. APCLSV shows substantial sequence variability and has been recovered from various Prunus sources coming from seven countries, an indication that it is likely to have a wide geographical distribution.
\end{abstract} tides [nt], missing only $\approx 30$ to $40 \mathrm{nt}$ of the $5^{\prime}$ terminal sequence) and the
The genus Trichovirus (27) comprises four species: the type member Apple chlorotic leaf spot virus (ACLSV), Cherry mottle leaf virus (CMLV), Peach mosaic virus (PcMV), and Grapevine berry inner necrosis virus (GINV). These viruses have elongated, highly flexuous particles 640 to $760 \mathrm{~nm}$ long and 10 to $12 \mathrm{~nm}$ wide. Their genome consists of a monopartite single-stranded (ss)RNA of positive polarity, 7.6 to $8 \mathrm{~kb}$ long, which harbors three overlapping open reading frames (ORFs) that encode an RNAdependent RNA polymerase (RdRp), a movement protein (MP) belonging to the $30 \mathrm{~K}$ superfamily (28), and a $22-$ to $28-\mathrm{kDa}$ coat protein (CP) (1). The genomes of CMLV and PcMV also encode an additional small ORF of unknown function. Trichoviruses can be transmitted by mechanical inoculation, grafting, and plant propagation. CMLV, PcMV, and probably GINV are transmitted in nature by eriophyid mites $(15,17)$, whereas no vector is known for ACLSV. The genus Trichovirus is included in the recently created family Flexiviridae (1), together with other viruses with flexuous, elongated viral particles and phylogenetically related, undivided ssRNA genomes belonging to the genera Allexivirus, Capillovirus, Carlavirus, Foveavirus, Mandarivirus, Potexvirus, and Vitivirus, as well as some viruses unassigned to any genus

Corresponding author: T. Candresse; E-mail address: tc @bordeaux.inra.fr

The nucleotide sequences reported here have been deposited as GenBank accession nos. AY713379 to AY713386 and AF413932.

* The $\boldsymbol{e}$-Xtra logo stands for "electronic extra" and indicates that the online version contains supplemental material not included in the print edition. The online supplement table contains primers used for the cDNA synthesis and polymerase chain reaction amplification of different regions of the Sus2 isolate of the Apricot pseudochlorotic leaf spot virus.

DOI: 10.1094/PHYTO-95-0420

(c) 2005 The American Phytopathological Society
(1). The recent creation of the family Flexiviridae was accompanied by a complete re-evaluation of the taxonomic criteria and, in particular, of the molecular criteria used for species discrimination. Extensive intraspecies and interspecies sequence comparison has led to the definition of species cut-off values of $72 \%$ nucleotide identity and $80 \%$ amino acid identity in the sequences of the complete CP or RdRp (1).

ACLSV, the type member of the genus Trichovirus, infects most of the fruit species belonging to the families Prunoidae and Maloidae (30). Being frequently symptomless in pome fruit, it can be responsible for serious diseases in stone fruit, including false plum pox (19), plum bark split (8), cherry fruit necrosis $(6,7)$, and "viruela" and "butteratura" diseases in apricot $(32,34)$. ACLSV also may cause tissue incompatibility and bud necrosis if infected material is used for grafting in nurseries $(6,7)$. Complete nucleotide sequences have been reported for the P863 (plum bark split), P205 (apple topworking disease), PMB1 (false plum pox), and Balaton1 (cherry necrosis) isolates $(11,12,18,36)$.

PcMV and CMLV naturally infect peach and cherry, respectively, causing distinct diseases in these hosts. They are transmitted by distinct eriophyid mite species but appear to be closely related in genome structure and sequence, $\mathrm{CP}$ size, doublestranded (ds)RNA profiles, and serological cross-reactivity $(15,16)$.

Recently, a survey of Prunus material from southern Italy affected by diseases of unclear etiology was carried out using a polyvalent polymerase chain reaction (PCR) assay allowing the detection of viruses belonging to the genera Trichovirus, Capillovirus, and Foveavirus (9). The presence, in a mixed infection, of ACLSV and of an uncharacterized filamentous virus possibly belonging to the genus Trichovirus was detected in two independent sources, a Japanese plum source (Sus2) with severe stem pitting or grooving symptoms and an apricot source (ARPox1) with symptoms resembling those described for the Apricot ringpox 
disease $(23,24,33)$. This report presents a detailed characterization of this new agent, including the complete sequencing of the genome of the Sus2 plum isolate and the partial sequencing of the ARPox 1 apricot isolate. These results provide evidence that this new virus, for which the name Apricot pseudo-chlorotic leaf spot virus is proposed, is a member of the genus Trichovirus closely related to ACLSV.

\section{MATERIALS AND METHODS}

Virus isolates and samples. The Sus2 and ARPox1 isolates were obtained from plum (Prunus salicina cv. Shiro) and apricot $(P$. armeniaca $\mathrm{cv}$. Bulida) trees, respectively, from Southern Italy $(23,24)$ and were propagated under greenhouse conditions by grafting on GF305 peach seedlings. The ACLSV Prunus isolates used are part of the collection maintained at INRA Bordeaux (France). Samples of two plum ( $P$. salicina) plants, cvs. Black Beaut and Angeleno, showing severe stem grooving symptoms, and of one apricot plant, cv. Baracca, showing butterarura (34) symptoms on fruit, were collected from commercial orchards in Campania (southern Italy). The plum sample $\operatorname{Tr} 1$ ( $P$. domestica var. Satsuma), showing severe symptoms of decline and stem grooving of the Myrobolan 29C rootstock, was collected in a commercial orchard in the Goulburn Valley (Australia) (35).

Determination of the herbaceous host range. The Sus2 isolate and the P863, PMB1, and Balaton1 ACLSV isolates were mechanically transmitted to Nicotiana occidentalis 37B using young, symptomatic GF305 leaves as the inoculum. Leaves were ground $(1 / 4, \mathrm{wt} / \mathrm{vol})$ in $30 \mathrm{mM}$ potassium phosphate buffer, $\mathrm{pH}$ 7.0, as described (17). Before transmission, activated charcoal (VWR, Fontenay-sous-Bois, France) at $90 \mathrm{mg} / \mathrm{ml}$ and $2.5 \%$ (vol/vol) nicotine hemisulfate (Sigma-Aldrich, St. Louis) were added to the homogenates. Carborundum (400 mesh) was used as the abrasive. The following plants were evaluated as potential hosts: Chenopodium album, C. amaranticolor, C. foetidum, C. murale, C. quinoa, N. clevelandii, N. debnei, N. glutinosa, N. tabacum cvs. Samsun and Xanthi, N. rustica, Phaseolus vulgaris cv. Vedette, and Lycopersicum esculentum cv. Rutgers. The appearance of symptoms was monitored over a 3-week period.

Serological analyses. The Sus2 isolate was compared serologically with ACLSV-P863, ACLSV-PMB1, and ACLSV-Balaton1 isolates. For the sake of comparison, all viruses were propagated in $N$. occidentalis 37B. Double-antibody sandwich enzyme-linked immunosorbent assay (DAS-ELISA) tests were performed using immunoglobulins from the $\mathrm{P} 2$ polyclonal antiserum against the P863 ACLSV isolate (INRA, Bordeaux, France) or using a commercial kit (Bioreba AG, Reinach, Germany). Triple-antibody sandwich (TAS)-ELISA assays were carried out using the antiP863 antiserum as trapping antibody and the 29.13 and 8.20 monoclonal antibodies (MAbs) developed by INRA against the P863 ACLSV isolate as secondary antibodies. All ELISA procedures were according to Alioto et al. (2). For the TAS-ELISA, the purified 29.13 and 8.20 MAbs were diluted to final concentrations of 1.5 and $1 \mu \mathrm{g} / \mathrm{ml}$, respectively. The secondary antibody, goat anti-mouse immunoglobulin alkaline $\mathrm{G}(\mathrm{IgG})$ phosphatase conjugate, was used at a 1:5000 dilution. The optical densities (ODs) were measured at $405 \mathrm{~nm}$ with a Bio-Rad 3550 Microplate Reader (Richmond, CA) at intervals from $20 \mathrm{~min}$ to $2 \mathrm{~h}$. Values above three times the average obtained for healthy samples were assumed to indicate infected samples. Each test was repeated at least twice.

Immunosorbent electron microscopy. Carbon-coated 200mesh electron microscopy grids were coated for $15 \mathrm{~min}$ at $25^{\circ} \mathrm{C}$ with $\mathrm{P} 2$ antiserum diluted 1:1,000 in $0.1 \mathrm{M}$ phosphate buffer, $\mathrm{pH}$ 7 , and then rinsed with the same buffer. $N$. occidentalis $37 \mathrm{~B}$ leaves infected by the Sus2 isolate were homogenized in $0.1 \mathrm{M}$ phosphate buffer, $\mathrm{pH} 7$ (1/5, wt/vol), and coated grids floated on the homogenate for $25 \mathrm{~min}$ at $25^{\circ} \mathrm{C}$. The grids then were rinsed with distilled water, stained with $2 \%$ sodium phosphotugstate (PTA), pH 7, and examined using a Philips EM301 electron microscope operating at $80 \mathrm{kV}$.

Nucleic acids extraction. Total RNAs were extracted from infected or healthy GF305 and N. occidentalis 37B leaves using the silica-capture procedure described by Foissac et al. (9). Viral dsRNAs were purified from the same plant tissues as described previously (10).

Determination of the complete nucleotide sequence of the Sus2 isolate. Short internal cDNA fragments were generated using the degenerated oligonucleotide primer (DOP) random PCR strategy (37) on purified viral dsRNAs from infected $N$. occidentalis 37B as described by Gentit et al. (10). The amplification products were purified using the Nucleotrap kit (Clontech, Erembodegem, Belgium), cloned in the pGEM-T Easy vector (Promega, Lyon, France) following the manufacturer's instructions, and finally electroporated into Escherichia coli XL1 cells (Stratagene, Amsterdam, the Netherlands). All cloned fragments were commercially sequenced (Genome Express, Grenoble, France) on both strands.

Primers were designed from the sequence of the short internal DOP cDNAs and used in long-distance reverse-transcription PCR (LD-RT-PCR) performed on purified viral dsRNAs with the Advantage polymerase mix as recommended by the supplier (Clontech). The 3' terminal region between the polyvalent PDO (9) PCR fragment and the polyA tail was amplified in a similar fashion using an LD-polyT primer with $(\mathrm{dT})_{25}$ at its $3^{\prime}$ end. The $3^{\prime}$ terminal region of the virus present in the ARPox1 source was amplified in a similar fashion. The various PCR products were purified, cloned, and finally sequenced as described above.

The 5' terminal region of the Sus 2 isolate genome was cloned in three successive steps. The first two steps involved a $5^{\prime}$ random amplification of cDNA ends (RACE) strategy using the LD-CAP primer and the Clontech commercial kit. The last step involved the GSP6 primer designed from the sequence of the 5'-most RACE clone (RC4) and a second, degenerate primer (NCR1), designed from a consensus sequence generated from the alignment of the $5^{\prime}$ noncoding regions (5'NCR) of CMLV and of the P205, PMB1, P863, and Bal1 ACLSV genomes. This primer covers positions 33 to 51 of the CMLV genome and positions 15 to 34 of the ACLSV genome.

Sequence assembly and analysis. The full-length sequence of the Sus2 isolate genome was assembled from the various overlapping cDNA fragments and its genomic organization deduced using the suite of programs available at the Infobiogen website. Database searches were performed using the BLAST facility of NCBI. Pairwise sequence comparisons and genetic distance calculations were performed using the MEGA program (22).

Multiple alignments and phylogenetic reconstructions were performed using CLUSTAL W (38) and phylogenetic trees were displayed using the Treeview program (31). The following viral sequences were used for comparison: ACLSV-P863 (M58152), ACLSV-P205 (D14996), ACLSV-PMB1 (AJ243438), ACLSVBalaton1 (X99752), ACLSV-SX2 (AF251275), ACLSV-MK9 (AB060962), CMLV (AF170028), and GINV (D88448).

RT-PCR detection of ACLSV and of the new virus. ACLSVspecific detection by RT-PCR was performed using the A52 and A53 primers, as described by Candresse et al. (4). Nested RTPCR for the detection of the new virus was carried out using the primers and procedure described by Liberti et al. (23).

\section{RESULTS}

Comparison of Sus2 isolate and ACLSV symptoms in herbaceous host plants. Using the simple inoculation buffer suggested by James and Murkerji (17) for CMLV, the Sus2 isolate was transmitted by mechanical inoculation to $N$. occidentalis 37B. Despite the fact that the original Prunus samples were in 
mixed infection with ACLSV (described below), some plants were recovered in which only the Sus2 isolate was present, as demonstrated by repeated failure to detect ACLSV in the N. occidentalis plants by ACLSV-specific RT-PCR (4). Therefore, these plants were used as a pure source of the Sus2 isolate and compared with three reference ACLSV isolates (P863, PMB1, and Balaton 1) which had been transmitted to N. occidentalis. In this host, all viruses induced comparable symptoms, differing from isolate to isolate essentially by their severity (vein clearing, chlorotic spotting and mottling, and leaf deformation and curling). All viral isolates were inoculated to a range of potential herbaceous indicator plants in order to compare their host range and symptomatologies. No infection was detected for any of the viruses assayed in the following species: $C$. foetidum, $C$. murale, $N$. clevelandii, N. debnei, N. glutinosa, N. tabacum cvs. Samsun and Xanthi, N. rustica, Phaseolus vulgaris, and L. esculentum (data not shown). Failure of the viruses to accumulate in the inoculated leaves of these plants was verified by ELISA using polyvalent anti-ACLSV reagents which also detected the Sus2 isolate (described below). The Sus2 isolate also failed to accumulate in the other Chenopodium spp. assayed (C. album, C. amaranticolor, and $C$. quinoa). In contrast, all three ACLSV isolates induced necrotic local lesions on the inoculated leaves of all three Chenopodium spp. and systemic infection symptoms (chlorotic spots and rings, line patterns, leaf deformation, and so on) were observed on C. quinoa and C. amaranticolor (data not shown). Therefore, the herbaceous host range of the Sus2 isolate appears to be more restricted than that of ACLSV, for which $C$. quinoa and $C$. amaranticolor are well-known propagation hosts (25).

Cross-reactivity of the Sus2 isolate with ACLSV. The reactivity of the Sus2 isolate from $N$. occidentalis with serological reagents specific for ACLSV was evaluated by DAS- (for polyclonal antisera) and TAS- (for monoclonal antibodies) ELISA. Reference ACLSV isolates were used as controls and all viral isolates were propagated in $N$. occidentalis $37 \mathrm{~B}$ to facilitate comparison. The results obtained are presented in Table 1 and demonstrate that the Sus2 isolate is efficiently recognized by both ACLSV-specific polyclonal antisera used but is not recognized by the two monoclonal antibodies used, despite their broad specificity toward ACLSV isolates.

Morphology of Sus2 isolate particles. Using the P2 polyclonal antiserum against ACLSV, particles of the Sus2 isolate from $N$. occidentalis were trapped in immunosorbent electron microscopy (ISEM) assays. The viral particles were readily detected from infected $N$. occidentalis $37 \mathrm{~B}$ extracts but not from similar extracts prepared from healthy plants. The Sus2 isolate particles have an elongated, flexuous morphology similar to that of ACLSV or other members of the genus Trichovirus (Fig. 1).

Cloning and genome sequence analysis of the Sus 2 isolate. In addition to the initial small cDNA fragment obtained by a polyvalent nested RT-PCR assay (9) which revealed the originality of the Sus2 isolate (Fig. 2B, PDO fragment), three other short internal cDNA fragments were amplified from purified viral
dsRNAs using the DOP random PCR technique (10,37). Significant homology with the genomic sequence of ACLSV isolates allowed the tentative positioning of these short cDNA fragments (Fig. 2B, DOP7, 8, and 12) on the Sus2 genome. The sequences of these internal fragments then were used to design PCR primers for bridging the various gaps and for cloning the $5^{\prime}$ genomic regions RACE. For the $5^{\prime}$ region, two successive RACE experiments failed to reach the $5^{\prime}$ end of the genome (Fig. 2C). A degenerated PCR primer (NCR1) based on a short region of homology between known $5^{\prime}$ sequences of trichoviruses and equivalent to positions 15 to 34 of the ACLSV genome allowed the generation of a last $5^{\prime}$ PCR fragment (Fig. 2C, N1). The sequence of the Sus2 isolate genome finally was assembled from the various overlapping partial cDNAs (Fig. 2B and C). Overall, $\approx 27 \%$ of the sequence was determined on more than one cDNA clone. Very few mismatches (nine in total) between independent cDNA clones were observed in the regions sequenced more than once and, whenever such mismatches were observed, sequence from a third independent clone was used to generate the consensus used for the final genome sequence. The sequence obtained is 7,494 nucleotides (nt) long, excluding the $3^{\prime}$ polyA tail, and lacks a small (34 nt, including the NCR1 primer binding site if the Sus2 genome length is similar to that of ACLSV) but as yet unspecified number of $5^{\prime}$ nucleotides. Further efforts to obtain the complete sequence of the $5^{\prime}$ region of the Sus 2 genome through 5' RACE experiments have been unsuccessful thus far. The nucleotide sequence of the Sus2 isolate was deposited as GenBank accession no. AY713379.

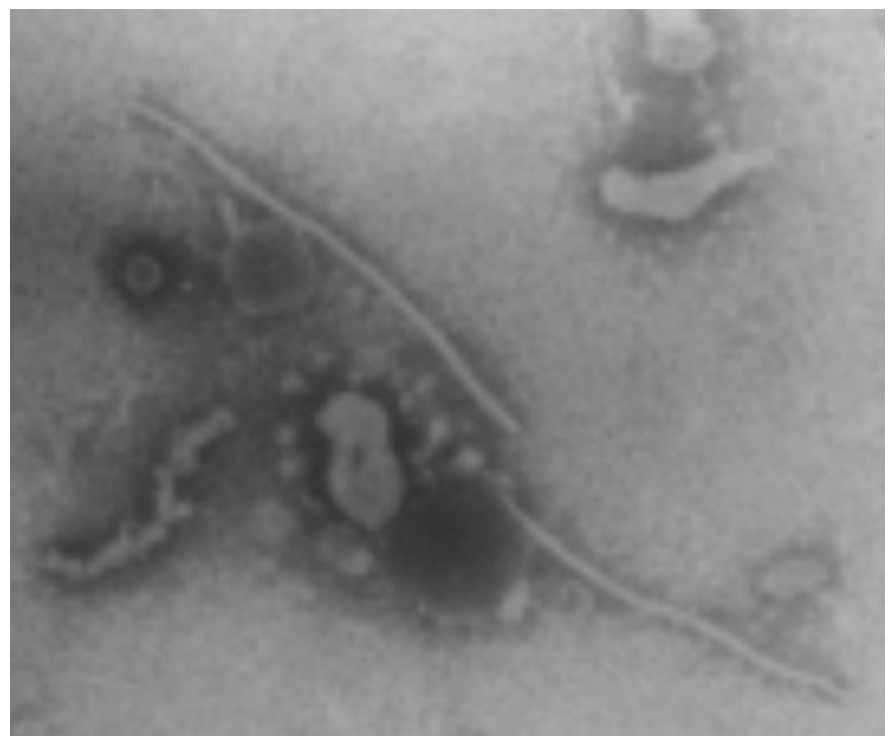

Fig. 1. Negatively stained particles of the Sus2 isolate observed after immunosorbent electron microscopy using an anti-Apple chlorotic leaf spot virus serum. The bar represents $100 \mathrm{~nm}$.

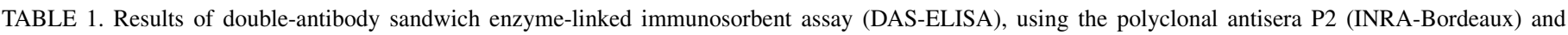
10/15 (Bioreba) and triple-antibody sandwich (TAS)-ELISA with two different monoclonal antibodies (MAbs 29.13 and 8.20$)^{\mathrm{a}}$

\begin{tabular}{|c|c|c|c|c|}
\hline \multirow[b]{2}{*}{ Sample ${ }^{b}$} & \multicolumn{2}{|c|}{ DAS-ELISA } & \multicolumn{2}{|c|}{ TAS-ELISA } \\
\hline & $\begin{array}{c}\text { P2 (Pab) } \\
\text { (INRA-Bordeaux) }\end{array}$ & $\begin{array}{c}\text { 10/15 }(\mathrm{Pab}) \\
(\text { Bioreba })\end{array}$ & $\begin{array}{c}8.20(\mathrm{MAb}) \\
\text { (INRA-Bordeaux) }\end{array}$ & $\begin{array}{c}29.13 \text { (MAb) } \\
\text { (INRA-Bordeaux) }\end{array}$ \\
\hline Healthy Nicotiana occidentalis & $0.011 \pm 0.007$ & $<0.001$ & $<0.001$ & $<0.001$ \\
\hline ACLSV-P863 in N. occidentalis & $>2$ & $0.59 \pm 0.004$ & $1.666 \pm 0.011$ & $0.914 \pm 0.357$ \\
\hline ACLSV-PMB 1 in $N$. occidentalis & $1.141 \pm 0.105$ & $>2$ & $0.688 \pm 0.037$ & $0.502 \pm 0.158$ \\
\hline ACLSV-Bal1 in N. occidentalis & $1.912 \pm 0.175$ & $0.809 \pm 0.038$ & $1.851 \pm 0.057$ & $>2$ \\
\hline APCLSV-Sus 2 in $N$. occidentalis & $1.243 \pm 0.095$ & $>2$ & $<0.001$ & $<0.001$ \\
\hline
\end{tabular}

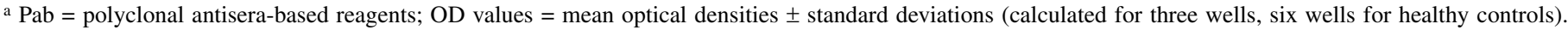

Standard deviations were not calculated for values $>2$ or $<0.001$.

b ACLSV = Apple chlorotic leaf spot virus and APCLSV = Apricot pseudo-chlorotic leaf spot virus. 
Genomic organization of the Sus2 isolate. A search for ORFs showed that the Sus 2 genomic RNA harbors three potential ORFs in its positive sense and that it has NCRs of 107 and $158 \mathrm{nt}$ at its $5^{\prime}$ and $3^{\prime}$ termini, respectively (Fig. 2A). However, the length of the $5^{\prime} \mathrm{NCR}$ is not known precisely due to the problems outlined above. No ORF of significant size was found on the negativesense strand. The initiating AUG codon for the first ORF was identified at positions 108 to 110 and is in a context (UACUAUGGGC) matching the consensus sequence for translation initiation in plants identified by Lutcke et al. (26). Another AUG codon is present upstream at positions 51 to 53, but it is followed closely by two in-frame TAA stop codons. A similar situation was identified in ACLSV P863 (11) and in CMLV (16). The three predicted overlapping ORFs encode proteins of 1,892 amino acids (aa) (ORF1, calculated molecular weight $216.1 \mathrm{kDa}$, positions 108 to 5,786), 457 aa (ORF2, $51.3 \mathrm{kDa}$, positions 5,698 to 7,071$)$, and 193 aa (ORF3, $21.5 \mathrm{kDa}$, positions 6,755 to 7,336$)$ (Fig. 2A).

Databank searches and computer-assisted comparisons of the deduced amino acid sequences of the proteins encoded by these three ORFs identified them as a potential replication-associated protein (RdRp) for the ORF1, a 30K superfamily-type (28) virus movement protein (ORF2), and a capsid protein (ORF3). The 21.5-kDa calculated molecular mass for the CP is in good agreement with the $\approx 20.5-\mathrm{kDa}$ value experimentally determined by Western blotting using anti-ACLSV immunoglobulins (data not shown). The RdRp showed all the conserved motives found in the corresponding proteins of the family Flexiviridae (1). These included a type I methyltransferase domain $(4,21)$ (amino acid positions 59 to 233), a potential papain-related thiol protease domain $(12,13)$ (amino acids 841 to 950 ), a helicase domain containing the seven conserved motifs characteristic of the superfamily I helicases (14) (amino acids 1,063 to 1,304), and finally the eight motifs characteristic of an RdRp of positive-stranded RNA viruses $(20,21)$ (amino acids 1,645 to 1,738$)$.

Therefore, the genomic organization of the Sus2 isolate is extremely close to those of the four completely sequenced ACLSV isolates, with a single potential difference. For three of these isolates (P863, PMB1, and Balaton 1), it has been reported that the CP ORF is included in frame within a larger ORF potentially initiated by an upstream ATG codon, resulting in an $\approx 28$-kDa protein identical in its C-terminal three-fourths with the $\mathrm{CP}$ itself (12). In the case of the fourth sequenced isolate, P205, the up- stream initiating codon was present but followed in frame by a TGA stop codon (36). The Sus2 isolate presents a similar situation, with an ATG at positions 6,554 to 6,556 but an in frame TAG at positions 6,635 to 6,637 .

Partial sequencing of the genome of the isolate present in the ARPox1 source. The 3 ' terminal region of the genome of the isolate of the new virus present in the ARPox 1 apricot source was amplified by LD-PCR using an LD-polyT primer and a primer designed from the sequence information of the PDO nested RTPCR fragment. The sequence deduced from this PCR product then was merged with that of the PDO fragment to generate a final contig of 2,591 nt, excluding the polyA tail (accession no. AY713380). As evaluated from the complete genome of the Sus2 isolate, this sequence represents approximately the $3^{\prime}$ terminal third of the complete genomic sequence of this second isolate.

The sequence from the ARPox 1 source has the same genetic organization as that of the Sus2 isolate (data not shown) and shows an overall nucleotide sequence identity of $84.6 \%$. It is strictly collinear with the Sus 2 sequence, with two exceptions affecting the 3' NCR: a 7-nt deletion corresponding to nucleotides 7,367 to 7,373 of the Sus2 sequence, and a 4-nt insertion just before the polyA tail, at the extreme 3 ' end of the genome.

Sequence comparisons with other members of the genus Trichovirus and determination of the phylogenetic affinities of the new virus. Preliminary analyses and database searches clearly positioned the new virus with the genus Trichovirus; therefore, all further detailed comparisons were limited to members of this genus. The overall nucleotide sequence identity levels calculated for the complete genomes were 66.7, 66.4, 65.9, and $65.8 \%$ for the P205, PMB1, P863, and Balaton1 isolates, respectively, of ACLSV; and only 59.8\% for CMLV and $55.1 \%$ for GINV. Surprisingly, values lower than these averages were observed for the $5^{\prime}$ and $3^{\prime}$ NCR (Table 2). In the $5^{\prime}$ NCR, the Sus2 isolate showed an average of only $\approx 49.4 \%$ identity with ACLSV isolates and $47.7 \%$ with CMLV. The corresponding values for the 3' NCR were 49 and $60.8 \%$ for ACLSV isolates and CMLV, respectively. Thus, it appears that, despite having an overall genome slightly closer to ACLSV than to CMLV, the Sus2 isolate has a $3^{\prime}$ NCR that is significantly more homologous to CMLV than to ACLSV.

Detailed comparisons also were performed on all three ORFs of the genome, both at the nucleotide and amino acid sequence levels (Table 2). In each case, a closer relationship was observed
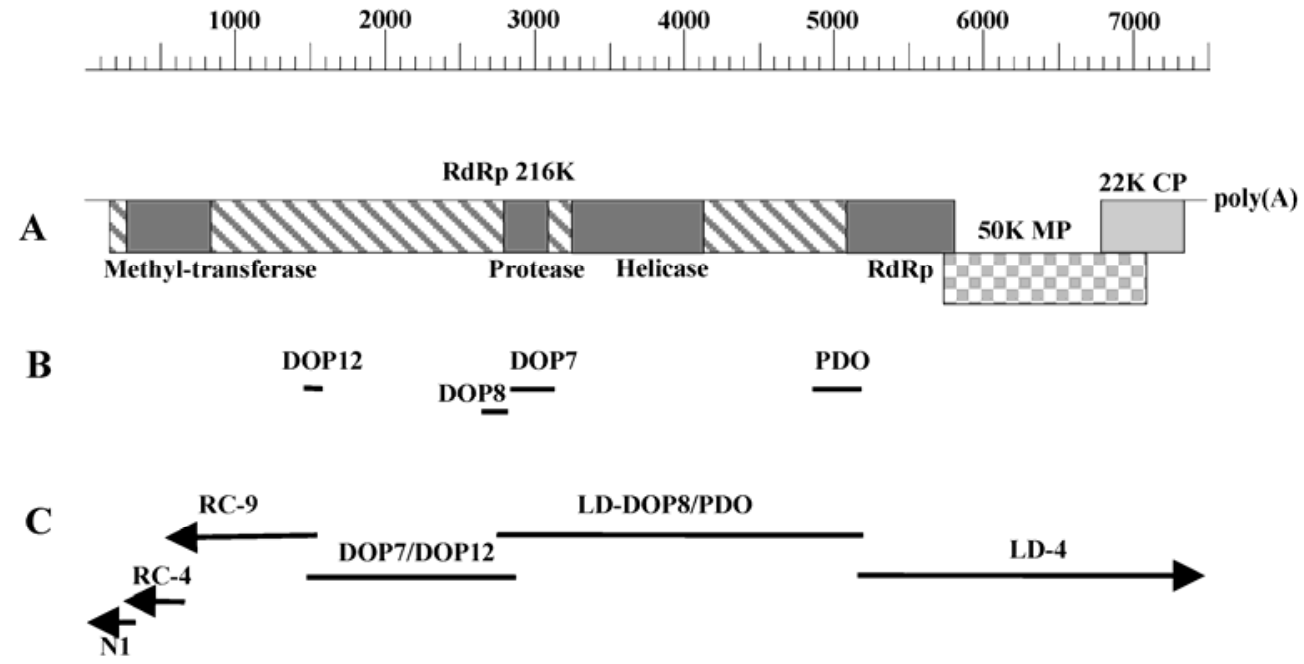

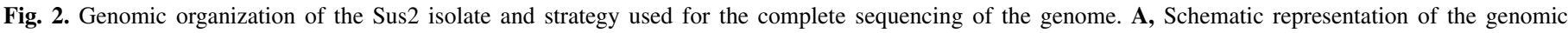

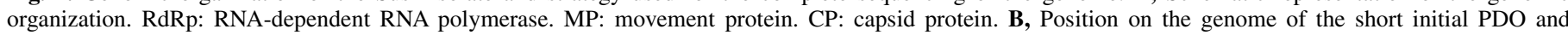

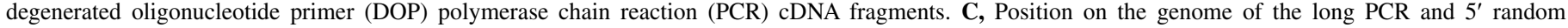

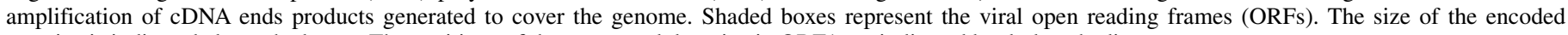
proteins is indicated above the boxes. The positions of the conserved domains in ORF1 are indicated by darker shading. 
TABLE 2. Average intraspecific and interspecific homology (identity) levels for the coding and noncoding regions of trichoviruses ${ }^{\mathrm{a}}$

\begin{tabular}{|c|c|c|c|c|c|c|c|c|}
\hline \multirow[b]{2}{*}{ Calculations ${ }^{\mathrm{b}}$} & \multicolumn{5}{|c|}{ Nucleotide sequences $(\%)$} & \multicolumn{3}{|c|}{ Amino acid sequences $(\%)$} \\
\hline & $\begin{array}{c}5^{\prime} \\
\mathrm{NCR}\end{array}$ & $\begin{array}{c}\text { ORF1 } \\
\text { (RdRp) }\end{array}$ & $\begin{array}{l}\text { ORF2 } \\
\text { (MP) }\end{array}$ & $\begin{array}{l}\text { ORF3 } \\
(\mathrm{CP})\end{array}$ & $\begin{array}{c}3^{\prime} \\
\mathrm{NCR}\end{array}$ & $\begin{array}{c}\text { ORF1 } \\
\text { (RdRp) }\end{array}$ & $\begin{array}{l}\text { ORF2 } \\
\text { (MP) }\end{array}$ & $\begin{array}{l}\text { ORF3 } \\
\text { (CP) }\end{array}$ \\
\hline Within ACLSV isolates & $85.3 \pm 2.2$ & $77.6 \pm 0.4$ & $80.1 \pm 0.8$ & $83.8 \pm 1.5$ & $78.1 \pm 2.4$ & $86.6 \pm 0.6$ & $80.8 \pm 1.4$ & $91.2 \pm 1.3$ \\
\hline Within APCLSV isolates & NA & NA & $83.6 \pm 1$ & $87.1 \pm 1.3$ & $89.4 \pm 2.5$ & NA & $86.0 \pm 1.5$ & $94.3 \pm 1.5$ \\
\hline Between APCLSV and ACLSV isolates & $49.4 \pm 1.2$ & $65.0 \pm 0.4$ & $66.6 \pm 1.1$ & $69.0 \pm 1.5$ & $49.0 \pm 3.3$ & $66.2 \pm 0.4$ & $57.3 \pm 2.1$ & $70.9 \pm 2.9$ \\
\hline Between APCLSV isolates and CMLV & 47.7 & $64.0 \pm 0.3$ & $61.6 \pm 0.8$ & $60.2 \pm 0.2$ & $60.8 \pm 2.9$ & $62.0 \pm 1.1$ & $45.6 \pm 0.1$ & $54.0 \pm 0.1$ \\
\hline Between APCLSV isolates and GINV & NA & NA & $48.5 \pm 0.7$ & $47.0 \pm 0.1$ & $39.5 \pm 0.7$ & NA & $35.6 \pm 0.2$ & $36.0 \pm 0.7$ \\
\hline
\end{tabular}

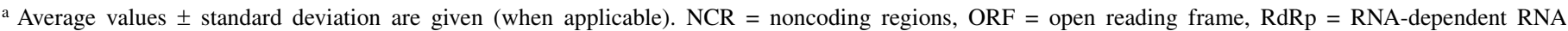
polymerase, $\mathrm{MP}=$ movement protein, $\mathrm{CP}=$ coat protein, and $\mathrm{NA}=$ not applicable (no sequence data available).

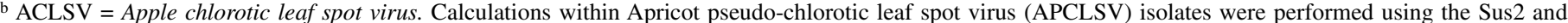
ARPox 1 sources sequences or only the Sus 2 sequence in cases when the ARPox 1 partial sequence did not cover the region considered. CMLV = Cherry mottle leaf virus and GINV = Grapevine berry inner necrosis virus .

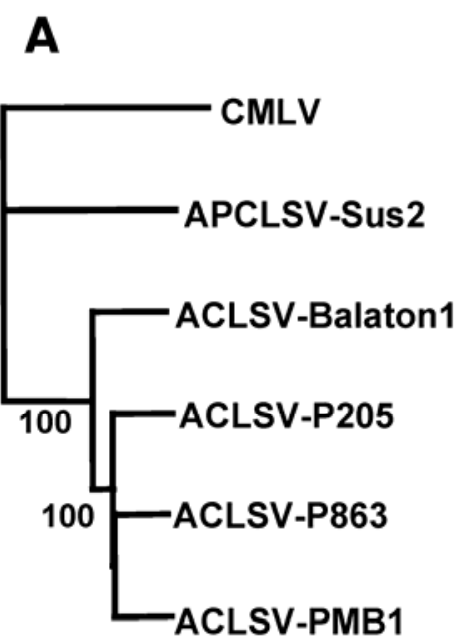

0.1

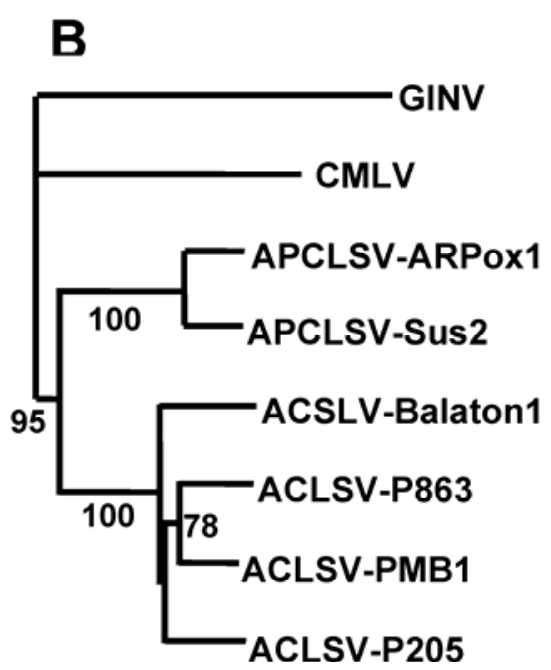

0.1

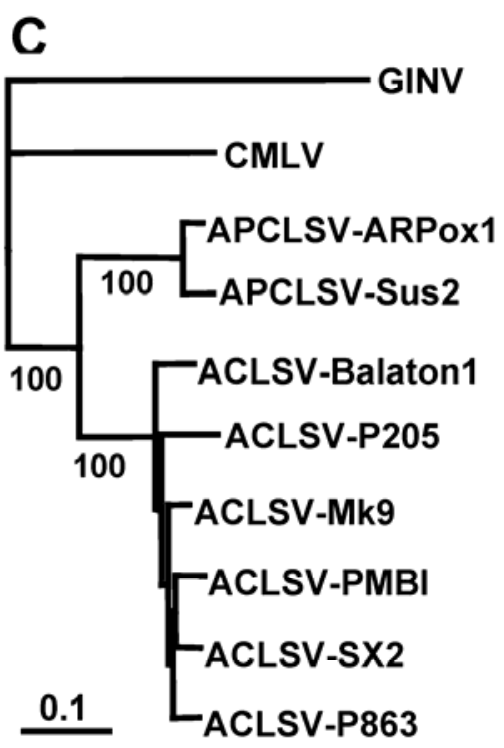

$\underline{0.1}$

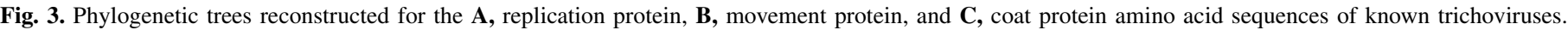

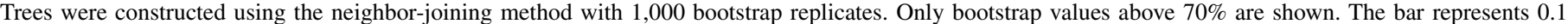

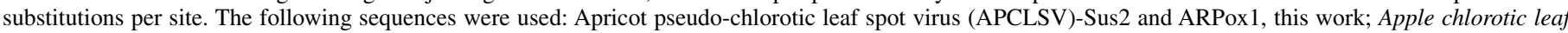

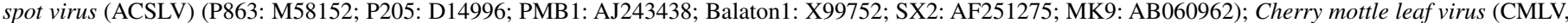
AF170028); and Grapevine berry inner necrosis virus (GINV, D88448).

with ACLSV isolates, but the average divergence level between the new virus isolate or isolates and ACLSV isolates always was significantly higher than the average divergence between ACLSV isolates (1.6- to 1.9-fold higher and 2.2- to 3.2-fold higher when comparing nucleotide and amino acid sequences, respectively) (Table 2). In particular, the Sus2 proteins were only, on average, 66.2\% (ORF1, RdRp), 57.3\% (ORF2, MP), and 70.9\% (ORF3, $\mathrm{CP}$ ) identical with those of ACLSV isolates.

This analysis is confirmed by the phylogenetic trees reconstructed for each of these proteins, which are shown in Figure 3. In each case (Fig. 3A to C), the Sus2 isolate (and, when available, the ARPox 1 isolate) clustered separately from known ACLSV sequences with very high bootstrap support. For both the MP and the CP trees, the new virus was found to be closer to ACLSV than to CMLV and GINV, again with strongly supported branches. Thus, the new virus appears to be distinct from ACLSV but closely related to it.

Detection of the new virus in other Prunus material. As a first step to evaluate the prevalence and geographical distribution of the new virus, collections of Prunus spp.-infecting viruses held at INRA Bordeaux and field samples from the Campania region of Italy were evaluated for the presence of the new virus using a specific nested RT-PCR assay. This assay uses primers within the region targeted by the polyvalent PDO assay (9) and selected using the Sus2 and ARPox 1 sequences so as to amplify isolates of the new agent but not isolates of ACLSV (23). Among the Bordeaux collections, the new virus was detected in only three accessions: A337 and A4, two apricot sources from France, and Bulida-64, an apricot source from Spain (data not shown). In each case, it was found to be in mixed infection with ACLSV. In parallel, a total of 42 field and collection samples from the Campania region (Italy) were assayed and the virus was detected in samples of two Japanese plum ( $P$. salicina Lindl) plants (cvs. Black Beaut and Angeleno), showing severe stem-grooving symptoms, and in one apricot plant (cv. Baracca), showing butteratura symptoms on fruit. These results were confirmed by sequence analysis of the 205-nt-long PCR products (accession nos. AY713381 to AY713385 and AF413932). Comparison of these new sequences among themselves and with the Sus2 and ARPox1 sequences showed nucleotide identity levels ranging from 79.1 to $98.2 \%$ and amino acid identity levels ranging from 92.5 to $100 \%$ (data not shown). The phylogenetic tree reconstructed from this limited sequence information is shown in Figure 4. It provides evidence for the existence of substantial sequence variability and of clustering of isolates within the populations of this new agent.

The virus recently was detected in Australia from a "Black Amber" Japanese plum tree showing distinct circular blotches on the skin of the ripening fruit and from declining Satsuma plum trees showing severe grooving of the Myrobolan 29C rootstock (35). A high homology was observed between a PCR-amplified 


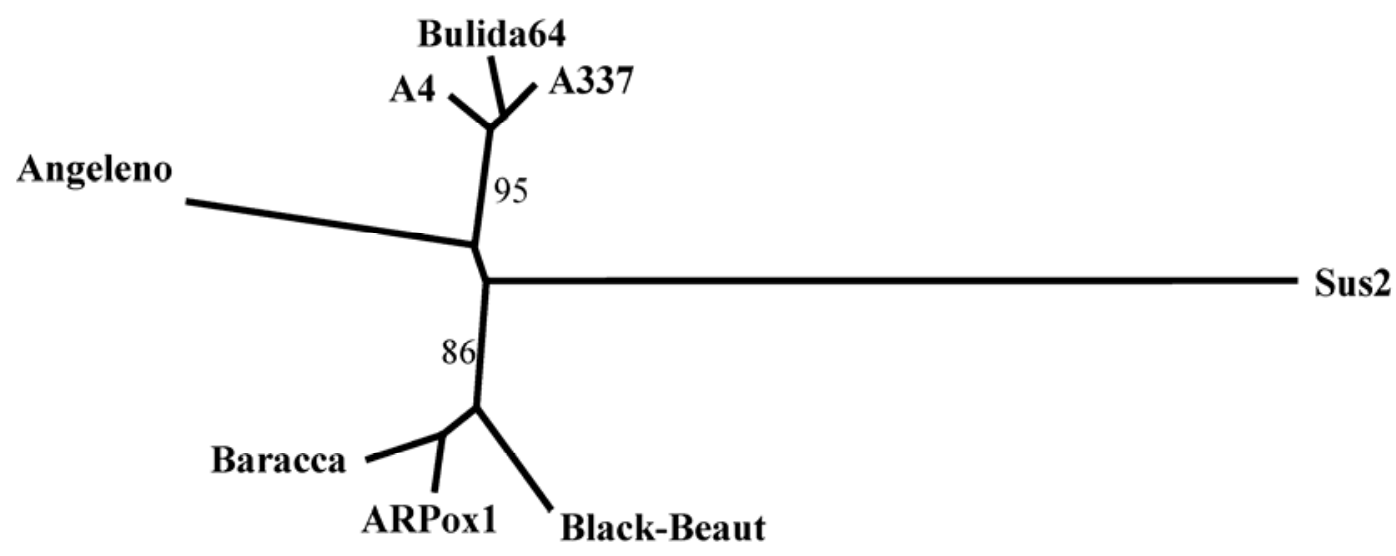

0.1

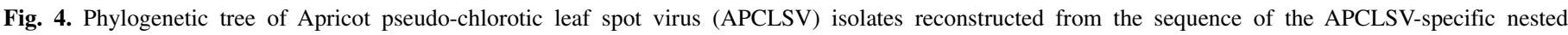

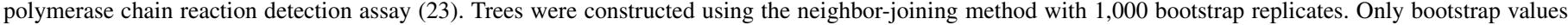
above $70 \%$ are shown. The bar represents 0.1 substitutions per site.

sequence from the Satsuma plum source and corresponding to the $3^{\prime}$ end of the genome (deposited under accession no. AY713386) and the Sus 2 sequence ( $85.7 \%$ identity, data not shown).

\section{DISCUSSION}

Initial evidence based on a short amplification product obtained using a polyvalent nested RT-PCR technique (9) indicated that the Sus2 and ARPox1 sources were infected by a viral agent belonging to the genus Trichovirus but distinct from ACLSV (23). The detailed characterization of the Sus2 isolate and the determination of the partial genome sequence for the ARPox1 isolate confirm and extend these first results. For both the RdRp gene and the CP gene, the nucleotide identity observed between the Sus 2 or ARPox 1 sequences and ACLSV isolates are below the $72 \%$ cutoff value recently proposed for distinct species in the family Flexiviridae (1). A similar situation applies to the amino acid sequences of these two proteins, which show identity values in the range of 65 to $73 \%$ compared with ACLSV isolates, whereas the cut-off value for species discrimination is $80 \%$ (1). Together with the phylogenetic reconstructions based on all three viral proteins (Fig. 3), these results strongly support the idea that the Sus2 and ARPox 1 sequences represent a new Trichovirus sp. distinct from ACLSV, for which the name Apricot pseudo-chlorotic leaf spot virus (APCLSV) is proposed, in order to highlight the close proximity of the new virus to ACLSV.

The differences in herbaceous host range and serology reported here further support this analysis. If verified on more APCLSV isolates, the inability to infect $C$. quinoa and $C$. amaranticolor may provide a useful discrimination technique and a way to separate ACLSV from APCLSV when the two viruses are encountered in mixed infection. Results with two polyclonal antisera raised against different ACLSV isolates clearly indicate that ACLSV and APCLSV are serologically related. This situation is similar to that encountered with CMLV and PcMV, which currently are regarded as two distinct but serologically related species in the genus Trichovirus (15). This cross-reactivity may explain, at least in part, why APCLSV escaped recognition for so long because any symptoms observed would have been ascribed to ACLSV. At present, the discrimination of the two viruses directly in Prunus samples can be achieved reliably only by ACLSV- and APCLSVspecific PCR assays $(4,23)$. The two ACLSV-specific MAbs 8.20 and 29.13 may be used to discriminate between these two agents. However, the availability of APCLSV-specific serological reagents would provide a very useful diagnostic tool and greatly assist in determining the prevalence, geographical distribution, and epidemiology of this new virus.

So far, APCLSV has been recovered from Prunus samples from Italy, Spain, France, and Australia. In addition, APCLSV appears to be present in other countries because comparisons of sequence data obtained by Al Rwahnih et al. (3) in a recent study of the genetic variability of ACLSV, using the ACLSV primers designed by Menzel et al. (29), indicated that four of the isolates tested (APR-EA5, an apricot source from Turkey [AJ586636]; PE154, a peach source from Hungary [AJ586650]; PE150, a peach source from Italy [AJ586645]; and PE297, a peach source from Jordan [AJ586651]) appear to represent, in fact, APCLSV isolates, with partial CP amino acid sequences 88 to $97 \%$ identical to the Sus2 and ARPox1 sequences reported here (data not shown).

APCLSV has been recovered so far from only a limited number of Prunus spp., including apricot, plum, Japanese plum, and peach, which are all known natural hosts of ACLSV. It will be interesting to see whether APCLSV has a broader natural host range, including cherry and species in the family Maloidae (apple, pear, quince, and so on), as is the case for ACLSV.

A key question, of course, is that of the symptoms that may be caused by APCLSV infection in its hosts. In a number of cases, APCLSV has been retrieved from source plants with severe symptoms on the wood (severe stem pitting or grooving on the Japanese plum Sus2 source [23], on the Italian Black Beaut and Angeleno Japanese plum, and on the Myrobolan 29C rootstock of the Satsuma plum from Australia [35]) or on the fruit (apricot ringpox-like symptoms of the ARPox1 source [23], butterarura symptoms on the apricot $\mathrm{cv}$. Baracca from Italy, and circular blotches on the skin of the Black Amber Japanese plum from Australia). In each case, APCLSV appears to be in mixed infection in these hosts, in particular with ACLSV. Therefore, it is not possible to ascertain which of the viruses present are responsible for the symptoms observed or even whether these symptoms are a consequence of the mixed infections. Further work is urgently needed, possibly involving the use of infectious cDNA clones to separate the various agents, before the pathogenicity of APCLSV in Prunus spp. can be understood.

\section{ACKNOWLEDGMENTS}

This study was supported in part by a bi-national Italy-France "Galileo" collaboration project and by a scientific grant of the Embassy of France in Italy to D. Liberti. We thank B. Batailler for the electron microscopy experiments; M. Al Rwahnih, D. Boscia, and A. Myrta 
(University of Bari, Italy) for fruitful discussions and for providing sequence information before publication; and K. Mayo for help in improving the English of the manuscript.

\section{LITERATURE CITED}

1. Adams, M. J., Antoniw, J. F., Bar-Joseph, M., Brunt, A. A., Candresse, T., Foster, G. D., Martelli, G. P., Milne, R. G., Zavriev, S. K., and Fauquet, C. M. 2004. The new plant virus family Flexiviridae and assessment of molecular criteria for species demarcation. Arch. Virol. 149:1045-1060.

2. Alioto, D., Gangemi, M., Deaglio, S., Sposato, P., Noris, E., Luisoni, E., and Milne, R. G. 1999. Improved detection of Citrus psorosis virus using polyclonal and monoclonal antibodies. Plant Pathol. 48:735-741.

3. Al Rwahnih, M., Turturo, C., Minafra, A., Saldarelli, P., Myrta, A., Pallás, V., and Savino, V. 2004. Molecular variability of Apple chlorotic leaf spot virus in different hosts and geographical regions. J. Plant Pathol. 86:117122.

4. Candresse, T., Lanneau, M., Revers, F., Grasseau, N., Macquaire, G., German, S., Malinovsky, T., and Dunez, J. 1995. An immunocapture PCR assay adapted to the detection and the analysis of the molecular variability of Apple chlorotic leaf spot virus. Acta Hortic. 386:136-147.

5. Candresse, T., Morch, M. D., and Dunez, J. 1990. Multiple alignment and hierarchical clustering of conserved amino acid sequences in the replication-associated proteins of plant RNA viruses. Res. Virol. 141:315-329.

6. Desvignes, J. C. 1999. Virus Diseases of Fruit Trees. Ctifl Ed., France.

7. Desvignes, J. C., and Boyé, R. 1988. Different diseases caused by the Chlorotic leaf spot virus on the fruit trees. Acta Hortic. 235:31-38.

8. Dunez, J., Marenaud, C., Delbos, R. P., and Lansac, M. 1972. Variability of symptoms induced by the Apple chlorotic leaf spot virus (CLSV). A type of CLSV probably responsible for bark split disease of prune trees. Plant Dis. Rep. 56:293-295.

9. Foissac, X., Svanella-Dumas, L., Dulucq, M. J., and Candresse, T. 2001. Polyvalent detection of fruit tree Tricho, Capillo and Foveaviruses by nested RT-PCR using degenerated and inosine containing primers (PDO RT-PCR). Acta Hortic. 550:37-43.

10. Gentit, P., Foissac, X., Svanella-Dumas, L., Peypelut, M., Macquaire, G., and Candresse, T. 2002. Molecular characterization of foveaviruses associated with the cherry necrotic mottle leaf disease and complete sequencing of an European isolate of Cherry green ring mottle virus. Arch. Virol. 147:1033-1042.

11. German, S., Candresse, T., Lanneau, M., Huet, J. C., Pernollet, J. C., and Dunez, J. 1990. Nucleotide sequence and genomic organization of Apple chlorotic leaf spot closterovirus. Virology 179:104-112.

12. German-Retana, S., Bergey, B., Belbos, R. P., Candresse, T., and Dunez, J. 1997. Complete nucleotide sequence of the genome of a severe cherry isolate of Apple chlorotic leaf spot trichovirus (ACLSV). Arch. Virol. 142:833-841.

13. Gorbalenya, A. E., and Koonin, E. V. 1993. Helicases: Amino acid sequence comparisons and structure-function relationship. Curr. Opin. Struct. Biol. 3:419-429.

14. Gorbalenya, A. E., Koonin, E. V., and Lai, M. M. C. 1991. Putative papain-related proteases of positive-strand RNA viruses. FEBS Lett. 288:201-205

15. James, D., and Howell, W. E. 1998. Isolation and partial characterization of a filamentous virus associated with Peach mosaic virus disease. Plant Dis. 82:909-913.

16. James, D., Jelkmann, W., and Upton, C. 2000. Nucleotide sequence and genome organisation of Cherry mottle leaf virus and its relationship to members of Trichovirus genus. Arch. Virol. 145:995-1007.

17. James, D., and Mukerji, S. 1993. Mechanical transmission, identification, and characterization of a virus associated with mottle leaf in cherry. Plant Dis. 77:271-275.

18. Jelkmann, W. 1996. The nucleotide sequence of a strain of Apple chlorotic leaf spot virus (ACLSV) responsible for plum pseudopox and its relation to an apple and plum bark split strain. (Abstr.) Phytopathology 86(suppl.): S101.

19. Jelkmann, W., and Kunze, L. 1995. Plum pseudopox in German plum after infection with an isolate of Apple chlorotic leaf spot virus causing plum line pattern. Acta Hortic. 386:122-125.

20. Koonin, E. V. 1991. The phylogeny of RNA-dependent RNA-polymerases of positive-strand RNA viruses. J. Gen. Virol. 72:2197-2206.

21. Koonin, E. V., and Dolja, V. V. 1993. Evolution and taxonomy of positive strand RNA viruses: Implications of comparative analysis of amino acid sequences. Crit. Rev. Biochem. Mol. Biol. 28:375-430.

22. Kumar, S., Tamura, K., Jakobsen, I. B., and Nei, M. 2001. MEGA2: Molecular evolutionary genetics analysis software. Bioinformatics 17:12441245.

23. Liberti, D., Marais, A., Svanella-Dumas, L., Gentit., P., Ragozzino, A., and Candresse, T. 2003. Identification of a new Trichovirus in some fruit trees infected by Apple chlorotic leaf spot virus (ACLSV). Abstr. 19th Int. Symp. Virus Virus-Like Dis. Temperate Fruit Crops, Valencia, Spain.

24. Liberti, D., Marais, A., Svanella-Dumas, L., Gentit., P., Ragozzino, A., and Candresse, T. 2003. Biological properties and partial molecular characterization of an apricot strain of CGRMV Abstr. 19th Int. Symp. Virus Virus-Like Dis. Temperate Fruit Crops, Valencia, Spain.

25. Lister, R. M. 1970. Apple chlorotic leaf spot virus. No. 30 in: CMI AAB Description of Plant Viruses. CMI/AAB, Kew, UK.

26. Lutcke, H. A., Chow, K. C., Mickel, F. S., Moss, K. A., Kern, H. F., and Scheele, G. A. 1987. Selection of AUG initiation codons differ in plants and animals. EMBO J. 6:43-48.

27. Martelli, G. P., Agranovsky, A. A., Bar-Joseph, M., Boscia, D., and Candresse, T. 2000. Genus Trichovirus. Pages 956-960 in: Seventh Report of the International Committee on Taxonomy of Viruses. M. H. V. Van Regenmortel, C. M. Fauquet, D. H. L. Bishop, E. B. Carstens, M. K. Estes, S. M. Lemon, J. Maniloff, M. A. Mayo, D. J. McGeoch, C. R. Pringle, and R. B. Wickener, eds. Academic Press, San Diego, CA.

28. Melcher, U. 2000. The ' $30 \mathrm{~K}$ ' superfamily of viral movement proteins. J. Gen. Virol. 81:257-266.

29. Menzel, W., Jelkmann, W., and Maiss, E. 2002. Detection of four apple viruses by multiplex RT-PCR assays with coamplification of plant mRNA as internal control. J. Virol. Methods 99:81-92.

30. Ogawa, J. M., Zehr, E. I., Bird, G. W., Ritchie, D. F., Uriu, K., and Uyemoto, J. K. 1995. Compendium of Stone Fruit Diseases. The American Phytopathological Society, St. Paul, MN.

31. Page, R. D. 1996. TREEVIEW: An application to display phylogenetic trees on personal computers. Comput. Appl. Biosci. 12:357-358

32. Penas-Iglesias, A., and Ayuso, P. 1973. Preliminary identification of the viruses producing apricot pseudo-pox (viruela) and apricot mosaic diseases. Acta Hortic. 44:255-265.

33. Ragozzino, A., Alioto, D., and Zoina, A. 1992. Apricot Ring-pox-like disease and related disorders of apricot fruits in Campania. Acta Hortic. 309:359-362.

34. Ragozzino, A., and Pugliano, G. 1974. La butteratura delle albicocche. Indagini preliminary sulla eziologia. Riv. Ortoflor. Ital. 58:136-145.

35. Sarec, R., Moran, J., and Rodoni, B. 2003. An association of Apple chlorotic leaf spot virus strains with tree decline in plum. Abstr. 7.81, 8th Int. Congr. Plant Pathol., Christchurch, NZ.

36. Sato, K., Yoshikawa, N., and Takanashi, T. 1993. Complete nucleotide sequence of the genome of an apple isolate of Apple chlorotic leaf spot virus. J. Gen. Virol. 74:1927-1931.

37. Telenius, H., Carter, N. P., Bebb, C. E., Nordenskjold, M., Ponder, B. A., and Tunnacliffe, A. 1992. Degenerate oligonucleotide-primed PCR: General amplification of target DNA by a single degenerate primer. Genomics 13:718-25.

38. Thompson, J. D., Higgins, D. G., and Gibson, T. J. 1994. CLUSTAL W: Improving the sensitivity of progressive multiple sequence alignment through sequence weighting, positions-specific gap penalties and weight matrix choice. Nucleic Acids Res. 22:4673-4680. 